\title{
Participation of special group people in household and personal care activities and problems faced by them
}

\section{Deepika Bisht}

Department of Family Resource Management, College of Home Science, Punjab Agricultural University, Ludhiana-141004 (Punjab), India

E-mail:deepshelly@gmail.com

\begin{abstract}
The present study was performed to examine the participation of female wheelchair users in household and personal care activities, problems faced by them and to seek suggestions from them to improve their work environment. The study was conducted in Punjab state and the sample was selected from different districts of Punjab by using snowball and purposive sampling technique. Only those female wheelchair users were selected for the study who were involved in performing household work. Case studies on 10 female wheelchair users were done to gather relevant information from the respondents and their work participation profile was observed for three consecutive days. A self-structured questionnaire was prepared to gather the relevant data from the respondents. Results revealed that despite their physical limitations, respondents were involved in some of the activities in their homes. Difficulties experienced by respondents while performing household and personal care activities included poor eye sight, slow speed, early onset of fatigue and less light in the work area.
\end{abstract}

Keywords: Household activities, Participation, Personal-care activities, Wheelchair users, work participation

\section{INTRODUCTION}

According to 2011 census (2016 updated), there were about 1.18 crore women with disabilities representing 44 per cent of total disabled population of India (Anonymous, 2017). Women with disabilities are the most marginalized in Indian society. They are deprived of political, social, economic and health opportunities. Both disability and gender are physical constructs that totally ignore the personhood. To be a disabled woman is to be considered unable to fulfil the role of homemaker, wife as also mother, and unable to conform to the stereotype of beauty and femininity in terms of physical appearance. But yes, being a disabled woman also fits well into the stereotype of passivity and dependency.

The general attitude is still that a disabled woman has little hope of becoming a wife or a mother. Thus, the normal tendency among the laymen is to visualize the women with disabilities as a burden on her family, society or the state - a dependant for the rest of her life.

The integration of the disabled into the able bodied population, being more widely propagated, requires shaping common life and work environment for these populations, making allowances for the psycho-physical limitations of the physically challenged (Jarosz, 1996). According to National

\section{Article Info}

DOI:10.31018/jans.v10i2.1762

Received: February 22, 2018

Revised: March 31, 2018

Accepted: April 28, 2018

\section{How to Cite}

Bisht, D. (2018). Participation of special group people in household and personal care activities and problems faced by them. Journal of Applied and Natural Science, 10(2): 667- 671 
performing household work. . Case studies were done to gather relevant information from the respondents. For conducting the case studies, 10 female wheelchair users who were involved in household work were purposively selected and their work participation profile was observed for three consecutive days. A self-structured questionnaire was prepared to gather the relevant data from the respondents, which was pre-tested on five women other than the respondents of the study and the necessary changes were incorporated in the questionnaire. The interview schedule had questions related to extent of participation of female wheelchair users in household and personal care activities, energy and time demand and difficulties faced by respondents while performing these activities. They were also asked to rank the suggestions so as to improve their work environment. Data was then collected through personal interview and observation method using the structured interview schedule and the data was analysed in the form of mean, frequency and percentages.

\section{RESULTS AND DISCUSSION}

Extent of participation of respondents in household and personal care activities: Despite their physical limitations, respondents were actively involved in some of the activities in their homes. Table 1 gives information about their participation in various household and personal activities. Majority $(80 \%)$ of the respondents peeled and cut vegetables sometimes and found doing it average in terms of complexity. Dal/rice was cleaned by about $60 \%$ of the respondents and they would do it almost always, though they found doing it a bit complex. Similar results were found in a study by Bhalla (1997) as he concluded that elderly were actively participating in cooking, dishwashing, dusting and ironing activities but their participation in other household activities was less. Sandhu (2001) in a study on elderly women revealed that 89.16 per cent of the respondents did peeling and chopping of vegetables, 85 per cent respondents also did the job of folding of washed clothes and 79.16 per cent did mending of their clothes themselves.

Eighty per cent of the respondents always would do knitting and found doing it average in complexity. Regarding personal care activities, all the respondents would always bath, dress, comb hair and eat by themselves as these activities are less complex to perform. About $70 \%$ of the respondents always took medicine and found it average in complexity to remember the medicine schedule. Haynes and Raven (1962) carried out a study on 95 old people and found out that besides house work, they were engaged in knitting, needle work, reading and watching television. Majority of the respondents did their house work without help, even those who were seriously handicapped. Pennathur et al (2003) in a study also reported that older women found performing household and personal tasks difficult because these tasks involved reaching, twisting and bending of trunk.

Affective component of worker input while participating in household and personal care activities: The affective component concerns the worker's personal feelings about the activity, his attitudes and interests, his preferences and dislikes. These aspects may contribute to the homemaker's feelings of working hard or easily. Feelings of working easily may contribute to greater satisfaction with the work. Feelings of working hard may be directly related to the unhappy feeling that we are doing more than necessary to accomplish the work (Steidl and Bratton 1968).

Table 2 indicates that only $30 \%$ of the respondents liked peeling and cutting vegetables as they were not comfortable while performing these activ-

Table 1. Extent of participation of respondents in household and personal care activities.

\begin{tabular}{llll}
\hline Activities & Respondents & Frequency & Complexity score \\
\hline Kitchen & & & \\
\hline Cutting vegetables & $8.00(80.00)$ & 1.47 & 2.12 \\
Peeling vegetables & $8.00(80.00)$ & 1.47 & 2.12 \\
Cleaning dall rice & $6.00(60.00)$ & 1.67 & 2.30 \\
\hline Clothing Care & & & \\
\hline Mending clothes & $5.00(50.00)$ & 1.60 & 2.20 \\
Folding clothes & $6.00(60.00)$ & 1.33 & 1.16 \\
Doing embroidery & $4.00(40.00)$ & 1.25 & 2.00 \\
Doing knitting & $8.00(80.00)$ & 1.62 & \\
\hline Personal Care & & & 2.00 \\
\hline Dressing & $10.00(100.00)$ & 2.00 & 1.00 \\
Bathing & $10.00(100.00)$ & 2.00 & 2.14 \\
Combing hair & $10.00(100.00)$ & 2.00 & 2.10 \\
Taking medicine & $7.00(70.00)$ & 1.70 & 1.00 \\
Eating & $10.00(100.00)$ & 2.00 & . \\
Reading & $3.00(30.00)$ & 1.33 & Complext: Easy=1,
\end{tabular}

Note: Figures in parentheses indicate percentage, Frequency: Sometimes=1, Always=2, Complexity: Easy=1, Average $=2$, Complex $=3$ 
Table 2. Affective component of worker input while participating in household and personal care activities.

\begin{tabular}{lll}
\hline Activities & Like & Comfortable \\
\hline Kitchen & & \\
\hline Cutting vegetables & $3(30)$ & $1(10)$ \\
Peeling vegetables & $3(30)$ & $1(10)$ \\
Cleaning dals/ rice & $4(40)$ & - \\
\hline Clothing care & & \\
\hline Mending clothes & $4(40)$ & $3(30)$ \\
Folding clothes & $4(40)$ & $5(50)$ \\
Doing embroidery & $4(40)$ & $1(10)$ \\
Doing knitting & $8(80)$ & $1(10)$ \\
\hline Personal care & & \\
\hline Dressing & $10(100)$ & $3(30)$ \\
Bathing & $10(100)$ & $3(30)$ \\
Combing hair & $10(100)$ & $10(100)$ \\
Taking medicine & - & $5(50)$ \\
Eating & $10(100)$ & $2(20)$ \\
Reading & $3(30)$ & $1(30)$ \\
\hline
\end{tabular}

Note: Figures in parentheses indicate percentage

Table 3. Energy and time demands on respondents while participating in household and personal care activities.

\begin{tabular}{lll}
\hline Activities & $\begin{array}{l}\text { Demand } \\
\text { energy } \\
\text { (mean score) }\end{array}$ & $\begin{array}{l}\text { on } \\
\text { time } \\
\text { (mean score) }\end{array}$ \\
\hline Kitchen & & \\
\hline Cutting vegetables & 2.62 & 2.62 \\
Peeling vegetables & 2.62 & 2.62 \\
Cleaning dals/ rice & 2.3 & 1.12 \\
\hline Clothing Care & & \\
\hline Mending clothes & 1.4 & 2 \\
Folding clothes & 1.6 & 1.6 \\
Doing embroidery & 1.25 & 3 \\
Doing knitting & 1.50 & 3.00 \\
\hline Personal Care & & \\
\hline Dressing & 1.5 & 1.8 \\
Bathing & 1.5 & 1.4 \\
Combing hair & 1.1 & 1.4 \\
Taking medicine & 1 & 2.3 \\
Eating & 1.3 & 2.3 \\
Reading & 1 & \\
\hline
\end{tabular}

Demand on energy: Low $=1$, Appropriate $=2$, High=3; Demand on time: Less time consuming=1, Appropriate=2, Extremely time consuming $=3$ ities. Almost $80 \%$ of the respondents liked knitting and only $10 \%$ were comfortable while doing it. All the respondents liked bathing, dressing and eating by themselves but most were uncomfortable performing them, which might be due to the lack of hand rails and grab bars in their bathroom and absence of other special requirements of them.

Energy and time demands on respondents while participating in household and personal care activities: It can be observed in Table 3 that most of the respondents experienced high demand on energy and time while peeling and cutting vegetables. Demand on energy was appropriate while cleaning dal/rice and respondents felt this activity was less time consuming. Adjei and Brand (2018) in a study also found that older women were involved in various household activities such as cooking, house cleaning and shopping, and allocated more time for cooking and house cleaning activities. Mending clothes, eating and reading put low demand on energy but were appropriately time consuming as perceived by respondents. Demand on energy and time while folding clothes was appropriate. Doing embroidery and knitting, though, put low demand on energy but were extremely time consuming. Dressing, bathing, combing hair and taking medicine, all these activities required low energy and varied from less time consuming (combing hair and taking medicine) to appropriately time consuming (dressing and bathing).

Difficulties experienced by respondents while participating in household and personal care activities: People with special needs have special requirements and so they face more difficulties while performing any work in the environment not designed according to their needs. Table 4 indicates that 60 per cent of the respondents suffered from poor eye sight and had slow speed while peeling and cutting vegetable, 40 per cent suffered from early onset of fatigue and 20 per cent had less light in the work area. Poor eye sight became an obstacle for 50 per cent of the respondents while doing knitting also they had insufficient

Table 4. Difficulties experienced by respondents while participating in household and personal care activities.

\begin{tabular}{lllll}
\hline Activities & Poor eye sight & Slow speed & Early onset of fatigue & Less light in work area \\
\hline Cutting vegetables & $6(60)$ & $6(60)$ & $4(40)$ & $2(20)$ \\
Peeling vegetables & $6(60)$ & $6(60)$ & $4(40)$ & $2(20)$ \\
Cleaning dals/ rice & $2(20)$ & $2(20)$ & - & $2(20)$ \\
Mending clothes & $2(20)$ & $2(20)$ & $2(20)$ & $2(20)$ \\
Folding clothes & - & $4(40)$ & - & - \\
Doing embroidery & $1(10)$ & $1(10)$ & $1(10)$ & $4(40)$ \\
Doing knitting & $5(50)$ & $3(30)$ & $3(30)$ & $5(50)$ \\
Dressing & - & $7(70)$ & $7(70)$ & $4(40)$ \\
Bathing & - & $3(30)$ & - & $4(40)$ \\
Combing hair & - & $7(70)$ & $7(70)$ & - \\
Eating & - & $7(70)$ & - & $2(20)$ \\
Reading & $1(10)$ & $1(10)$ & - & \\
\hline
\end{tabular}

Note: Forgetting about taking medicine was also experienced by 4 respondents, Figures in parentheses indicate percentage 
light in the work area and 30 per cent had slow speed and also experienced early onset of fatigue. The most common problems experienced by the respondents while performing personal and household activities was slow speed followed by early onset of fatigue, which might be because they were working in poor posture because of the lack of special designing/features for them. In a study conducted by Kohli (2005) on elderly (single) living in rural and urban households, it was revealed that majority of female respondents from rural and urban area experienced physical problems viz. knee pain, difficulty in making frequent postural variations, uncomfortable working counters, improper lighting to work and difficulty in grasping and replacing the items as they were actively involved in home-making work in this very age also. Sandhu (2001) in her study also found that less light at work area imposed some difficulty in performance of the activities such as cleaning dals and mending.

Suggestions of respondents to make the workplaces comfortable: Kumar et al. (2012) in a study reported that a barrier-free environment enables people with disabilities to move about safely and freely and to be independent functioning member of the society in everyday activities. Bhalla (1997) in a study revealed that the major problems faced by the elderly were absence of railings/grab handles, too high working counters and storage shelves, slippery floor finishes, low height of electric switches, small sized rooms and unsuitable stairs. Ishihara et al. (2002) also found that handrails inside and outside of the home are considered useful in assisting elderly people who live independently. So, a list of suggestions, to avoid or overcome these problems, was made and the respondents were asked to rank them according to their preferences. The first preference was given a score of 10 , second was given a score of 9 and so on. The suggestion given at last i.e. tenth preference was, thus, given a score of one.

Table 5 reveals that all the respondents gave first preference to the suggestions that counter and wash basin height should be low, there should be free space below the counter for wheelchair foot plate and knee clearance and wheelchair should be made more comfortable as indicated by the mean score of 10 for each of the suggestions. Further, second preference was given to the suggestion that change in tools should be done for performing activities, followed by the suggestion that some provision should be made in the wheelchair to keep the wool balls while knitting to prevent them from falling and that there should not be any threshold or steps at doors and within the house followed by the suggestion of having something to hold for support while getting up and sitting on wheelchair, something to aid in turning lights on and off, proper light in entire house and some provision in wheelchair to keep food plate while eating food as indicated by the mean scores of $6.3,5.6,5.2$ and 5.0 respectively.

Suggestions like neck support, safety barrier in front of wheelchair, sink bowl should not be very deep, cover on wheelchair like pram, seat belt and provision to recline the seat backwards were given least preferences by the respondents as indicated by the mean scores of $4.7,4.1,4.0,3.3,3.3$ and 2.7 respectively.

\section{Conclusion}

From the present study it can be concluded that

Table 5. Suggestions of respondents, along with preferences, to help them work comfortably.

\begin{tabular}{lll}
\hline Suggestions & $\begin{array}{l}\text { No. of } \\
\text { Respondents }\end{array}$ & Preferences \\
\hline Counters and wash basin height should be low & $10(100)$ & 10 \\
Free space below counters for wheelchair foot plate and knee clearance & $10(100)$ & 10 \\
No threshold or steps at doors & $8(80)$ & 8.7 \\
Something to hold for support while getting up and sitting on wheelchair & $9(90)$ & 6.3 \\
Proper light in entire house & $9(90)$ & 5.2 \\
Some place in wheelchair to keep wool balls while knitting & $8(80)$ & 8.7 \\
Sink bowl should not be very deep & $6(60)$ & 4.0 \\
Something to aid in turning lights on and off & $7(70)$ & 5.6 \\
Some provision in wheelchair to keep food plate while eating food & $7(70)$ & 5.0 \\
Cover on wheelchair like pram & $6(60)$ & 3.3 \\
Provision to recline the seat backwards & $6(60)$ & 2.7 \\
Neck support & $7(70)$ & 4.7 \\
Seat belt & $6(60)$ & 3.3 \\
Safety barrier in front & $7(70)$ & 4.1 \\
Wheelchair should be more comfortable & $10(100)$ & 10 \\
Change in tools for performing various activities & $10(100)$ & 9.5 \\
\hline
\end{tabular}

Note: Figures in parentheses indicate percentage, Preferences: Ist Preference-10, IInd Preference-9, IIIrd Preference- 8, IVth Preference- 7, Vth Preference- 6, VIth Preference- 5, VIIth Preference- 4, VIIIth Preference- 3, IXth Preference- 2, Xth Preference- 1 
the most frequently performed activity by majority $(80 \%)$ of the respondents was of peeling and chopping vegetables. However, only 30 per cent of the respondents liked peeling and chopping vegetables as they were not comfortable while performing these activities. All the respondents were also uncomfortable while taking bath, dressing themselves and eating by themselves because people with special needs require an environment designed according to their needs, which was absent in the households of the respondents. Some of the suggestions given by respondents included low work counters and wash basin height, free space below the counter for wheelchair foot plate and knee clearance, wheelchair should be made more comfortable.

\section{REFERENCES}

Adjei, N.K. and Brand, T. (2018). Investigating the associations between productive housework activities, sleep hours and self-reported health among elderly men and women in western industrialised countries. BMC Public Health. 18:110.

Anonymous (2017). Disabled Population in India as per census 2011 (2016 updated). http://enabled.in/wp/ disabled-population-in-india-as-per-census-2011-2016updated/ (retrieved on 30.03.2018)

Bhalla, M. (1997). Anthropometric measurements of the elderly for designing of household equipment, furniture and workplaces.M.Sc. Thesis,Punjab Agricultural University, Ludhiana, India.

Haynes, K.J. and Raven, J. (1962). The living pattern of some old people, Garston, Watsford, Herts: Building Research Station; Miscellaneous Paper no. 40 cited in: Grandjean E; 1973; Ergonomics of the home; London; Taylor and Francis Ltd; pp. 314-15.

Ishihara, K., Nagamachi, M., Komatsu, K., Ishihara, S., Ichitsubo, M., Mikami, F., Osuga, Y., Imamura, K. and Osaki, H. (2002). Handrails for the elderly: A survey of the need for handrails and experiments to determine the optimal size of staircase handrails. Gerontechnology. 1(3): 175-189.

Jarosz, E. (1996) Determination of the workspace of wheelchair users. International J Industrial Ergonomics. 17: 123-133.

Kohli, N. (2005). Problems of elderly (single) living in rural and urban households.M.Sc. Thesis, Punjab Agricultural University, Ludhiana, India.

Kumar, M. (2006). National Policy for Persons with Disabilities. Ministry of Social Justice and Empowerment.http://www.aicb.org.in/images/advocacy/ advocacyResources/National\%20Policy\%20for\% 20Persons\%20with\%20Disabilities.pdf (retrieved on 30.03.2018).

Kumar, A., Sharad, K.S. and Anwer, S. (2012). Difficulties faced by the wheelchair users in accessing automated teller machine (ATM): A case study. Ind J Physiotherapy and Occupational Therapy-An International J., 6:142-44.

Pennathur, A., Sivasubramaniam, S. and Contreras, L.R. (2003). Functional limitations in Mexican American elderly. Int J Industrial Ergonomics. 31: 41-50.

Sandhu, P.(2001).Physiological stresses in elderly women of urban Punjab and technologies to reduce them. Ph.D Thesis, Punjab Agricultural University, Ludhiana.

Steidl, R.E. and Bratton, E.C. (1968).Work in the home. New York, London, John Wiley and Sons. 